\title{
DIMENSIONALLY STABLE WATER-BLOWN POLYURETHANE FOAM EXTENDED WITH BIO-BASED PROPYLENE GLYCOL AND MODIFIED WITH PAPER WASTE SLUDGE
}

\author{
Agnè KAIRYTÉa ${ }^{\mathrm{a}}$, Aiga IVDRE ${ }^{\mathrm{b}}$, Saulius VAITKUS ${ }^{\mathrm{c}}$

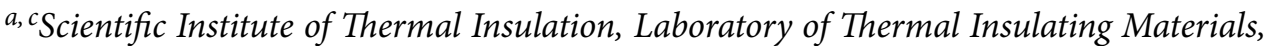 \\ Vilnius Gediminas Technical University, Linkmenu st. 28, LT-08217 Vilnius, Lithuania \\ ${ }^{b}$ Polymer Laboratory, Latvian State Institute of Wood Chemistry, \\ Dzerbenes st. 27, LV-1006 Riga, Latvia
}

Received 28 November 2016; accepted 23 December 2016

\begin{abstract}
Paper waste sludge (PWS) is the main and the greatest by-product in paper production process, and its elimination as well as destruction is a primary environmental problem. This research explores the feasibility of such wastes to be used in polyurethane foam composites. It is well known that using water as a sole blowing agent has major drawbacks such as long demould time, shrinkage, high diffusion rate of carbon dioxide and etc.; therefore, the bio-based propylene glycol (RPG) is used in order to solve such problems. The addition of 20 parts by weight (pbw) of RPG eliminates the primary shrinkage of the foam composites when PWS is used in the amount varying from $5 \%$ to $20 \%$, and improves the dimensional stability at $70{ }^{\circ} \mathrm{C}$ and $90 \%$ relative humidity conditions. The addition of titanate coupling agent modified PWS particles increases the compressive strength of the final composites from $\sim 26 \%$ to $\sim 53 \%$, from $\sim 17 \%$ to $\sim 31 \%$ and from $\sim 3 \%$ to $\sim 23 \%$ for, respectively, 10 pbw, 15 pbw and 20 pbw RPG extended foam composites.
\end{abstract}

Keywords: polyurethane, paper waste sludge, composites, bio-based materials, propylene glycol, shrinkage, strength, dimensional stability.

\section{Introduction}

The negative impact on the environment may be reduced by using renewable resources which have a great potential in replacing traditional polymers produced from petroleum feedstocks (Belgacem, Gandini 2008; Alagi et al. 2016). Vegetable-based oils are renewable resource which may be used as a primary material for the development of products which are characterised by various structural and functional variations. Abundance, accessibility and relatively low cost make vegetable oils an attractive raw material in the plastics' industry. These oils and fatty acids obtained thereof are considered as the most important renewable raw materials in chemical industry and production of eco- logical-functional polymers and polymeric materials (Miao et al. 2014; Alam et al. 2014; Pillai et al. 2016).

For the production of vegetable oil-based polyols, conversion of $\mathrm{C}=\mathrm{C}$ double bonds or ester groups into hydroxyl groups is necessary. Such methods are analysed using various oils, e.g. palm (Pawlik, Prociak 2011), soy (Gu, Sain 2013), rapeseed (Kurańska et al. 2015), castor (Wik et al. 2011) and even molasses (Hatakeyama et al. 2011), corn, potato starches and wheat (David et al. 2009). In order to replace petroleumbased polyols with polyols from vegetable oils, they must conform certain requirements raised for polyols used in the production of polyurethane foams, i.e. they

Corresponding author:

A. Kairytė E-mail: agne.kairyte@vgtu.lt 
must have corresponding functionality $(>3)$, molecular weight $(<1200 \mathrm{~g} / \mathrm{mol})$ and hydroxyl value varying from $350 \mathrm{mg} \mathrm{KOH} / \mathrm{g}$ to $600 \mathrm{mg} \mathrm{KOH} / \mathrm{g}$ (Pawar et al. 2016). Whereas polyurethane foams from vegetable oil-based polyester polyols are characterised by excessive shrinkage after production and poor dimensional stability when water is used as a blowing agent (European Comission 2013), scientists use fillers, chain extenders or cross-linking agents in order to overcome such problems.

Pollution prevention in paper production industry is a worldwide aspiration (Directive 2008/98/EC). One of the main aims of European Commissions and Directives is to transform European Union countries into "recycling community" which is capable of reducing the accumulation of wastes and using them in different processes. Paper waste sludge (PWS) is the main and the greatest by-product in paper production process (approx. 35\% of the produced paper (Frías et al. 2015)), and its elimination and destruction is primary environmental problem. Gluth et al. (2014) have determined that the main components in $\mathrm{PWS}$ are $\mathrm{SiO}_{2}$ and $\mathrm{Al}_{2} \mathrm{O}_{3}$ from kaolinite and $\mathrm{CaO}$ from calcium carbonate. Scientists Sá e Sant'Anna et al. (2008) have conducted a research on the impact of the main PWS component - calcium carbonate on the properties of flexible polyurethane foam. The obtained results have shown that increasing the amount of $\mathrm{CaCO}_{3}$ (particles size of $(100-250) \mu \mathrm{m})$ from $1 \mathrm{wt} . \%$ to $30 \mathrm{wt} . \%$, uniform distribution worsens due to overmuch variation in particles' size, particles are tend to agglomerate owing to non-uniform distribution of attraction forces between the filler and polymer matrix. It is as well determined that immoderate amount of calcium carbonate increases the hysteresis and worsens the quality of the final product. For the production of flexible polyurethane foams, authors Agarry et al. (2015) have used fractioned calcium carbonate particles $(0.06 \mu \mathrm{m}, 0.5$ $\mu \mathrm{m}, 3.5 \mu \mathrm{m}, 10 \mu \mathrm{m}, 20 \mu \mathrm{m}, 841 \mu \mathrm{m})$ as filler with the varying amounts from $5 \mathrm{wt} . \%$ to $40 \mathrm{wt} . \%$. They have determined that increasing amount of filler reduces tensile strength by $\sim 75 \%$ independently from the size of particles. Too much filler determines poor dispersion of particles and the formation of agglomerates what causes the stress concentration in polymeric matrix. The similar tendency of reducing tensile strength for flexible polyurethane foams reinforced with $\mathrm{CaCO}_{3}$ has been observed by Usman et al. (2012). Therefore, the application of some coupling agents and chain extenders such as titanates and propylene glycol from rapeseed glycerine (RPG) has been studied in order to overcome poor dispersion, non-uniformity of properties as well as excessive shrinkage after production and under the higher temperature and relative humidity conditions of reinforced and filled polyurethane foam composites.

The aim of this study is to choose the proper amount of water according to the requirements applied to factory made rigid polyurethane foams, and reduce the shrinkage by using chain extension with RPG and obtain PWS filled polyurethane foam composite characterised by sufficient dimensional stability and mechanical properties.

\section{Experimental}

\subsection{Materials and methods}

Polyester polyol synthesised from rapeseed oil by chemo-enzymatic route using lipase Novozym 435 (LLC IMD Technologies, Lithuania) is implemented. It has hydroxyl value of $323 \mathrm{mg} \mathrm{KOH} / \mathrm{g}$. For the research of shrinkage and dimensional stability, RPG (Dow, Germany) is used as co-polyol in the production of polyurethane foam. 4,4'-diphenylmethane diisocyanate Lupranat M20S (BASF, Germany) with the functionality of 2.7 and reactive groups' content of $31.5 \%$ is used as a hardener. In order to adjust the characteristic foaming times, blowing and gelling catalysts Lupragen N101 (BASF, Germany) and Lupragen DMI (BASF, Germany) are applied. Water is used as an ecological alternative for traditional blowing agents. Surfactant Tegostab B 1048 (Evonik, Germany) is used in order to obtain uniform structure. For the promotion of adhesion between polymer matrix and PWS particles, titanate coupling agent TCA-K44 (Capatue Chemical, China) is added. PWS particles are obtained from JSC Grigiskes, Lithuania. They are a mix wastes from hygienic and packing paper, honeycomb filler, corrugated cardboards as well as packages, and they form in the waste water cleaning equipment.

International standard ASTM D7487: 2016 is used in order to test polyurethane foams for cream, gel and tack-free times by cup test method. Length and width of specimens are determined according to EN 12085:2013, density - based on EN 1602 (2013) requirements. Compressive stress at $10 \%$ deformation or 
compressive strength up to $10 \%$ deformation (further compressive strength) and tensile strength are determined for specimens with the size of $(50 \times 50 \times 50) \mathrm{mm}$ in accordance with the requirements of EN 826:2013 and EN 1607:2013, respectively, using universal testing machine H10KS Hounsfield. The direction of loading during compression and tension is perpendicular to the foaming direction. Before the tensile strength determination, specimens have been glued to $(100 \times 50)$ $\mathrm{mm}$ sized metal plates and conditioned for $24 \mathrm{~h}$ at $(23 \pm 5){ }^{\circ} \mathrm{C}$ temperature and $(50 \pm 5) \%$ relative air humidity conditions. In order to obtain average value of compressive and tensile strengths, 10 specimens from each sample are tested. Primary shrinkage is evaluated for specimens having the size of $(400 \times 400 \times 50) \mathrm{mm}$ after $0.5 \mathrm{~h}$ and 1 day after production by measuring length and width at the same position. The numerical value of shrinkage is calculated according to Eq. (1):

$$
\Delta \varepsilon=\frac{b_{1}-b_{2}}{b_{1}} \cdot 100,
$$

where: $\Delta \varepsilon$ - shrinkage in the direction of length, width or thickness, \%; $b_{1}$ - length, width and thickness after $0.5 \mathrm{~h}$ after production, $\mathrm{mm} ; b_{2}$ - length, width and thickness after 1 day after production, mm. For the evaluation of average shrinkage, three specimens of each sample are tested. Dimensional stability test is carried out according to EN 1604:2013. Specimens have been held at $(70 \pm 2){ }^{\circ} \mathrm{C}$ temperature and $(90 \pm 5) \%$ relative humidity conditions for $48 \mathrm{~h}$ in climatic chamber Feutron 3522/51. For each sample, three specimens with the size of $(100 \times 100 \times 50) \mathrm{mm}$ are tested. In order to evaluate the impact of PWS on polyurethane foam composites' structure, scanning electron microscope (SEM) JEOL JSM-7600F with the resolution of $1.5 \mathrm{~nm}$ and magnification capability from 25 to 1000000 times is implemented. Before the test, specimens are coated with thin layer of gold under vacuum using apparatus QUORUM Q150R ES. For the calculation of percentage amount of closed cells, standard EN ISO 4590 (2 method) is used for three specimens from each composition. The size of specimens is of $(100 \times 30 \times 30) \mathrm{mm}$. Quantitative analysis of PWS is carried out using X-ray fluorescence spectroscopy method with Axios mAX. Particles have been compressed into $37 \mathrm{~mm}$ diameter tablets. Moisture content of PWS particles is determined with analyser A\&D MX-50. Three $10 \mathrm{~g}$ weighting specimens are used to obtain average value.

\subsection{Preparation of RPG extended and PWS modified polyurethane foam composites}

For the selection of proper amount of water, following amounts of water, pbw: $1.0 ; 1.5 ; 2.0 ; 2.5 ; 3.0 ; 3.5 ; 4.0$; $4.5 ; 5.0 ; 5.5 ; 6.0$ are used. Compositions of polyurethane foam and its composites are presented in Table 1 and Table 2.

Table 1. Composition of polyurethane foams modified with different amounts of water

\begin{tabular}{|l|c|}
\hline \multicolumn{1}{|c|}{ Material } & Amount of the materials, pbw \\
\hline \multicolumn{2}{|c|}{ Component A } \\
\hline Polyol & 100 \\
\hline Distilled water ${ }^{\mathrm{a}}$ & $1.0 ; 1.5 ; 2.0 ; 2.5 ; 3.0 ; 3.5 ; 4.0 ; 4.5 ; 5.0 ; 5.5 ; 6.0$ \\
\hline Lupragen N101 & 1.8 \\
\hline Lupragen DMI & 1.2 \\
\hline Tegostab B 1048 & 2 \\
\hline \multicolumn{2}{|c|}{ Component B } \\
\hline Isocyanate & Isocyanate index ${ }^{\mathrm{b}} 125$ \\
\hline
\end{tabular}

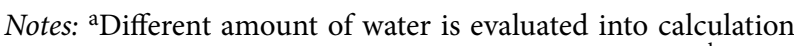
of isocyanate required to react with all hydroxyl groups; bisocy- $^{-}$ anate index is the ratio of equivalent and theoretical isocyanate amounts multiplied by 100 .

Table 2. Composition of polyurethane foam composites extended with RPG and modified with PWS

\begin{tabular}{|l|c|c|c|}
\hline \multirow{2}{*}{ Material } & \multicolumn{3}{|c|}{ Amount of $\mathrm{RPG}^{\mathrm{a}}$, pbw } \\
\cline { 2 - 4 } & 10 & 15 & 20 \\
\hline Component A \\
\hline Polyol & 90 & 85 & 80 \\
\hline Distilled water & 3 & 3 & 3 \\
\hline Lupragen N101 & 1.8 & 1.8 & 1.8 \\
\hline Lupragen DMI & 1.2 & 1.2 & 1.2 \\
\hline Tegostab B 1048 & 2 & 2 & 2 \\
\hline PWS/TCA K-44 (1\%) & $0 ; 5 ; 10 ; 15 ; 20$ wt.\% \\
\hline \multicolumn{4}{|c|}{ Component B } \\
\hline $\begin{array}{l}\text { Isocyanate } \\
\begin{array}{l}\text { Re-calculated amount of } \\
\text { water taking into account } \\
\text { moisture in RPG }\end{array}\end{array} \quad 2.76$ & 2.77 & 2.77 \\
\hline
\end{tabular}

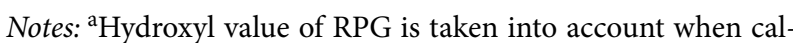
culating the required amount of isocyanate; ${ }^{b}$ Overall moisture content in polyol and RPG is recalculated for the amount of water needed to foam the specimens.

For the production of polyurethane foams with different amounts of water, polyol, catalysts and surfactant have been mixed for $1 \mathrm{~min}$ at a speed of 1800 $\mathrm{rpm}$. The obtained mixture has been divided into 10 equal portions. Into each of 10 parts, required amount 
of water has been poured. The final mixture of the materials is so called Component $\mathrm{A}$, and it has been mixed for another $1 \mathrm{~min}$ before the pouring a Component $\mathrm{B}$ - isocyanate.

For the production of polyurethane foam composites, 10 pbw, 15 pbw and 20 pbw of polyol is replaced by RPG. It has been mixed with polyol, catalysts, surfactant for $1 \mathrm{~min}$ at a speed of $1800 \mathrm{rpm}$. The obtained mixture has been divided into 3 equal portions. Into each of them, the required amount of water and titanate modified PWS particles are poured. The obtained Component $\mathrm{A}$ has been mixed for $1 \mathrm{~min}$ at the same speed. Further, scaled amount of Component $\mathrm{B}$ is added. The obtained mixture has been mixed for another $10 \mathrm{~s}$ and poured into $(400 \times 400 \times 100) \mathrm{mm}$ sized mould where it has been allowed to freely expand at $(23 \pm 5){ }^{\circ} \mathrm{C}$ temperature. The obtained samples have been stored for $24 \mathrm{~h}$, demoulded and cut into proper size specimens. Before the tests, specimens have been conditioned for $24 \mathrm{~h}$ at $(23 \pm 5){ }^{\circ} \mathrm{C}$ temperature and $(50 \pm 5) \%$ relative air humidity conditions.

\section{Results and discussion}

\subsection{Characterisation of PWS particles}

PWS particles are characterised by high moisture content (39\%), organic matter (wood (Fig. 1a), cellulose fibers, lignin and in some cases organic binder) and

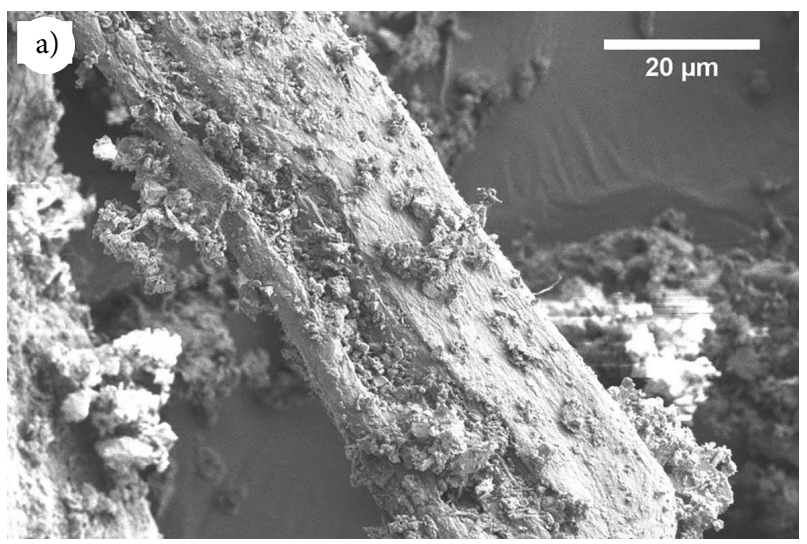

mineral loading (Fig. 1b) consisting of calcium carbonate $\left(\mathrm{CaCO}_{3}\right)$, kaolinite, talc, dolomite (Kairyte et al. 2016), however, chemical composition and physical properties vary depending on the quality of the paper, technology of waste water cleaning and fresh water usage specifics (Zule et al. 2007).

Milled and sieved through $0.63 \mathrm{~mm}$ sized sieve PWS particles have been exposed at $70^{\circ} \mathrm{C}$ temperature for $24 \mathrm{~h}$. The moisture content of dried particles is determined to be $1.5 \%$. Conducted quantitative analysis (Table 3) shows that the most of PWS particles consist of $\mathrm{CaCO}_{3}$ which in paper production industry is used as whiteness, stiffness and smoothness promoter.

It is previously determined (Kairyte et al. 2016) that the size of PWS particles varies from $0.4 \mu \mathrm{m}$ to $629 \mu \mathrm{m}$. Additionally to the results of quantitative chemical analysis made by X-ray fluorescence in $\mathrm{Ta}$ ble 3, there are $(21.1-24.3) \%$ of organic matter, i.e. cellulose, hemicellulose, lignin.

\subsection{Selection of water amount for the preparation of polyurethane foam composites}

For the production of polyurethane foam composites, the amount of water is determined according to the results of dimensional stability at $70^{\circ} \mathrm{C}$ temperature and 90\% relative humidity conditions (further dimensional stability), shrinkage after 1 day after production (further shrinkage) and apparent density. The conducted

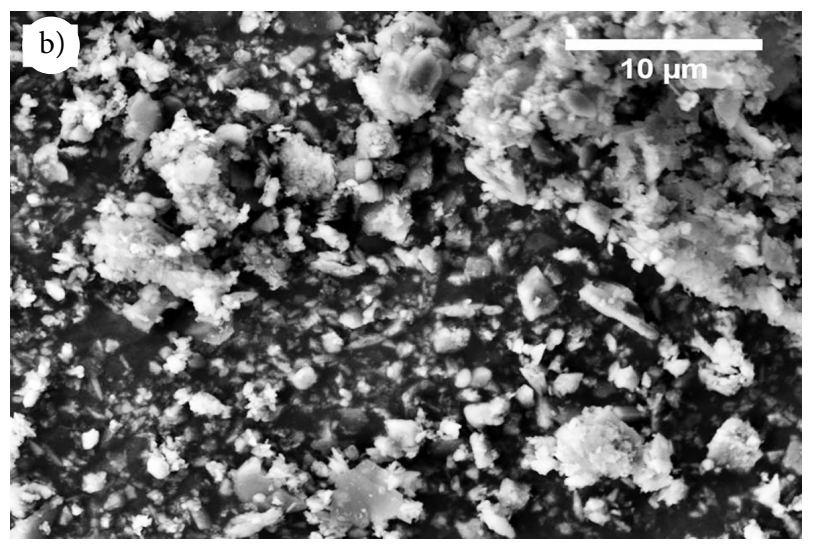

Fig. 1. SEM images of PWS particles: a) organic matter (magnification of $\times 2000)$; b) inorganic matter (magnification of $\times 3000)$

Table 3. Quantitative chemical composition of PWS particles

\begin{tabular}{|c|c|c|c|c|c|c|c|c|c|}
\hline \multicolumn{10}{|c|}{ Amount, wt.\% } \\
\hline $\mathrm{SiO}_{2}$ & $\mathrm{Al}_{2} \mathrm{O}_{3}$ & $\mathrm{CaO}$ & $\mathrm{MgO}$ & $\mathrm{Fe}_{2} \mathrm{O}_{3}$ & $\mathrm{Na}_{2} \mathrm{O}$ & $\mathrm{K}_{2} \mathrm{O}$ & $\mathrm{SO}_{3}$ & $\mathrm{P}_{2} \mathrm{O}_{5}$ & $\mathrm{O}_{\text {ther }}{ }^{\mathrm{a}}$ \\
\hline $5.8-$ & $4.6-$ & $48.5-49.5$ & $0.4-$ & $0.5-$ & $0.03-$ & $0.14-0.15$ & $0.17-0.20$ & $0.05-$ & $13.9-$ \\
6.0 & 4.8 & & 0.5 & 0.6 & 0.04 & & & 0.06 & 18.7 \\
\hline
\end{tabular}

Note: ${ }^{\mathrm{a}} \mathrm{Cl}, \mathrm{MnO}, \mathrm{NiO}, \mathrm{CuO}, \mathrm{ZnO}, \mathrm{Br}, \mathrm{Rb}_{2} \mathrm{O}, \mathrm{SrO}, \mathrm{BaO}, \mathrm{Nb}_{2} \mathrm{O}_{5}, \mathrm{Cr}_{2} \mathrm{O}_{3}$. 
research has shown that apparent density of polyurethane foam depends on the amount of water. Figure 2 shows the dependence of apparent density on the amount of water in Component A from 1.0 pbw to 6.0 pbw in step of $0.5 \mathrm{pbw}$.

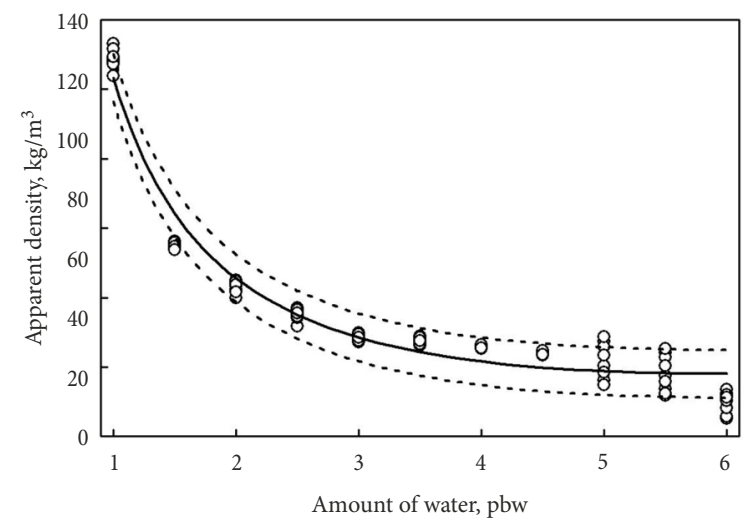

Fig. 2. The dependence of polyurethane foam's apparent density on the amount of water: $\bigcirc-$ experimental data; (----) - regression line (Eq. 2); (------) - prediction line

In order to evaluate the relationship between these two factors, mathematical-statistical analysis is conducted. It allows quantitative evaluation of the change in apparent density which depends on the change in the amount of water. Average values of polyurethane foam's apparent density may be described by regression equation (Eq. (2)) with the standard deviation of $S_{\bar{\rho} \rightarrow m}=5.32 \mathrm{~kg} / \mathrm{m}^{3}$ when $n=110$.

$$
\bar{\rho}=-1.861+3.252 \cdot m+\frac{122.9}{m},
$$

where: $\bar{\rho}$ - an average value of apparent density, $\mathrm{kg} / \mathrm{m}^{3}$; $m$ - the amount of water in Component A, pbw. Pre- dicted two-tailed confidence interval of the results is $\rho_{\text {pred. }}=\bar{\rho} \pm \delta$ with the possibility of $P=0.95$ and Student's criterion $t_{0.05}=1.66$ when $\alpha=0.05$ (Fig. 2 the dotted line). The obtained determination coefficient $R^{2}=0.958$ shows that polyurethane foam's apparent density by $95.8 \%$ depends on the amount of water and the rest $4.2 \%$ on other, e.g. technological factors.

Increasing the amount of water from 1.0 pbw to $6.0 \mathrm{pbw}$, apparent density has averagely reduced from $128.7 \mathrm{~kg} / \mathrm{m}^{3}$ to $30.1 \mathrm{~kg} / \mathrm{m}^{3}$, i.e. by approx. $76.6 \%$. Whereas $\mathrm{CO}_{2}$ gases form during the water and isocyanate reaction, increasing the amount of water increases the concentration of $\mathrm{CO}_{2}$ gases in air bubbles formed during the mixing. It determines greater foaming capability, thus foams are characterised by lower apparent density. The research of Thirumal et al. (2008) has shown that similar tendency of the change in apparent density when water amount is increased from $0 \mathrm{pbw}$ to $3.0 \mathrm{pbw}$ is observed. The density has averagely reduced from $116 \mathrm{~kg} / \mathrm{m}^{3}$ to $42 \mathrm{~kg} / \mathrm{m}^{3}$, i.e. by approx. $63.8 \%$. Comparing the results with other authors at water amounts varying from 1.0 pbw to 3.0 pbw, the average reduction in apparent density is, respectively, $53.3 \%$ and $62.3 \%$. The difference arises due to the use of different raw materials. It is as well observed from Figure 1 that scattering of apparent density results for polyurethane foams when the amount of water varies from $5.0 \mathrm{pbw}$ to $6.0 \mathrm{pbw}$ is sufficiently high. It may be attributed to non-homogeneity of the final product.

The additional research of dimensional stability and shrinkage has been conducted (Fig. 3). It may be observed that the increase in the amount of water from

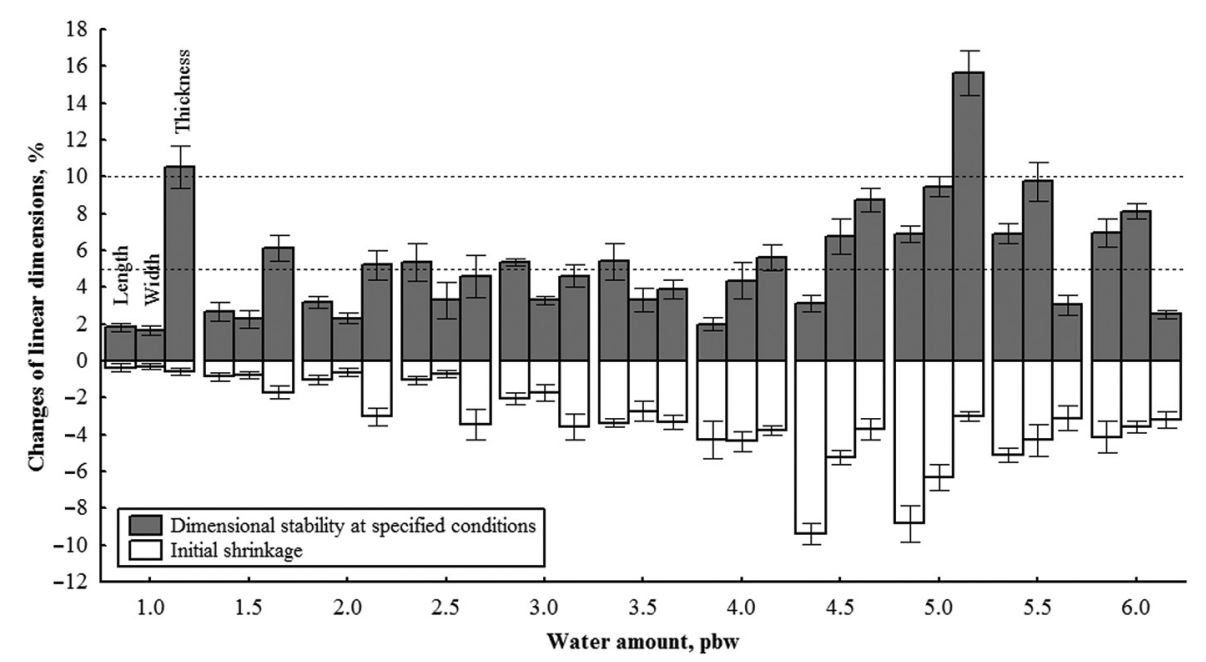

Fig. 3. The dependence of the change in polyurethane foam's linear dimensions on the amount of water: (-----) - maximum allowable changes in dimensions in the directions of length, width and thickness according to EN 13165:2012+A2:2016 
$1.0 \mathrm{pbw}$ to $6.0 \mathrm{pbw}$ increases the shrinkage. It means that the structure of the final product is not sufficiently stiff for the assurance of equilibrium in pressure difference between cellular structure and the surrounding environment. The intensity of these shrinkages depends on the amount of water used in the forming mixture as well as the nature of cellular structure (closed cell or open cell). The increase in the amount of water determines the polyurethane foams' structure characterised by larger closed cells as well as thinner cells' walls, and it means that the diffusion of $\mathrm{CO}_{2}$ gases through thinner walls is more intense, thus increasing the shrinkage of the final product (Xiaobin et al. 2008).

All materials more or less expand and shrink under the changing temperatures. Figure 3 presents the results which may be divided into the three main zones: from $1.0 \mathrm{pbw}$ to $3.0 \mathrm{pbw}$, from $3.5 \mathrm{pbw}$ to $5.0 \mathrm{pbw}$ and from $5.5 \mathrm{pbw}$ to $6.0 \mathrm{pbw}$. Conducted research on shrinkage shows the increase in the change of dimensions where the amount of water varies from $1.0 \mathrm{pbw}$ to $3.0 \mathrm{pbw}$. Polyurethane foams with the greatest apparent density have stiff cellular structure which is characterised by thicker walls. It constrains the penetration of $\mathrm{CO}_{2}$ gases into the surrounding environment what determines low shrinkage. However, the rest gases located in the cells of the product exposed to higher temperature and humidity diffuses out ruining the structure what influences the negative dimensional changes during the dimensional stability test, i.e. $0.4 \%$ from shrinkage test and additional $10.6 \%$ in the thickness direction from dimensional stability test when the amount of water during production is of $1.0 \mathrm{pbw}$.
Contrary tendency is observed for products where the amount of water varies from $3.5 \mathrm{pbw}$ to $5.0 \mathrm{pbw}$. It is explained by decrease in the amount of water needed to foam products with lower apparent density. As a consequence, cell walls in the structure become thinner, the rate of $\mathrm{CO}_{2}$ gases diffusion and their induced dimensional changes after production and during the dimensional stability test intensify. The reduction in the change of linear dimensions may be observed in the interval from $5.5 \mathrm{pbw}$ to $6.0 \mathrm{pbw}$. In case of lower amount of water, e.g. $5.0 \mathrm{pbw}$ and less, isocyanate amount in the forming mixture is sufficiently low in order to assure the compatibility, uniform mixing and proper reaction start time between these two components (Table 4).

Further increase in the amount of water increases the amount of isocyanate. This material is hydrophobic, consequently, increasing amount of it and water, does not assure the sufficient compatibility what is showed by delayed cream time. It means that the reaction rate of polymer formation is slower than the blowing rate. When the gel reaction finishes, polymeric carcass is not sufficiently firm in order to withstand the further growth of cells; therefore, partial destruction of cells is observed what results in an increase of open cell content. $\mathrm{CO}_{2}$ gases diffuse out of the product structure without ruining it due to partially open cell structure. Hereby, shrinkage and dimensional changes under higher temperature and humidity conditions are reduced. Evaluation of the obtained results for apparent density, shrinkage and dimensional stability indicates that the most suitable amount of water is $3.0 \mathrm{pbw}$.

Table 4. Characteristic foaming times and structural parameters of polyurethane foams

\begin{tabular}{|c|c|c|c|c|c|}
\hline \multirow{2}{*}{$\begin{array}{c}\text { Amount of water, } \\
\text { pbw }\end{array}$} & \multicolumn{5}{|c|}{ Parameter } \\
\cline { 2 - 6 } & Cream time, $\mathrm{s}$ & Gel time, $\mathrm{s}$ & Tack-free time, $\mathrm{s}$ & Cell size, mm & Closed cell content, \% \\
\hline 1.0 & $27 \pm 2$ & $91 \pm 2$ & $190 \pm 4$ & $0.125 \pm 0.03$ & $90.2 \pm 3.2$ \\
\hline 1.5 & $28 \pm 1$ & $98 \pm 3$ & $198 \pm 2$ & $0.130 \pm 0.04$ & $89.3 \pm 2.8$ \\
\hline 2.0 & $31 \pm 3$ & $98 \pm 1$ & $200 \pm 3$ & $0.132 \pm 0.05$ & $89.0 \pm 4.1$ \\
\hline 2.5 & $35 \pm 3$ & $99 \pm 2$ & $210 \pm 4$ & $0.145 \pm 0.03$ & $89.1 \pm 3.6$ \\
\hline 3.0 & $37 \pm 4$ & $102 \pm 4$ & $215 \pm 3$ & $0.152 \pm 0.02$ & $88.0 \pm 4.7$ \\
\hline 3.5 & $40 \pm 3$ & $114 \pm 4$ & $231 \pm 1$ & $0.201 \pm 0.04$ & $87.4 \pm 2.6$ \\
\hline 4.0 & $44 \pm 2$ & $118 \pm 2$ & $235 \pm 2$ & $0.264 \pm 0.03$ & $88.2 \pm 1.8$ \\
\hline 4.5 & $49 \pm 2$ & $124 \pm 3$ & $239 \pm 3$ & $0.320 \pm 0.06$ & $88.6 \pm 4.0$ \\
\hline 5.0 & $51 \pm 4$ & $131 \pm 3$ & $254 \pm 2$ & $0.476 \pm 0.05$ & $87.4 \pm 3.7$ \\
\hline 5.5 & $51 \pm 4$ & $134 \pm 3$ & $261 \pm 2$ & $0.558 \pm 0.06$ & $74.2 \pm 2.4$ \\
\hline 6.0 & $53 \pm 2$ & $139 \pm 2$ & $268 \pm 3$ & $0.720 \pm 0.06$ & $70.5 \pm 2.1$ \\
\hline
\end{tabular}




\subsection{Characterisation of RPG extended and PWS modified polyurethane foam composites}

The determined proper amount of water which is 3.0 pbw, is used for the following research of mechanical properties and shrinkage of PWS filled and RPG extended polyurethane foam composites. Density is one of the most important parameters which determines the all mechanical properties of almost all materials and its values depending on the amount of PWS are presented in Table 5 . It can be clearly seen that increasing amount of PWS increases the density of the obtained polyurethane foam composites. As it has been determined by the previous research of authors (Kairyte et al. 2016), the bulk density of PWS particles is $480 \mathrm{~kg} / \mathrm{m}^{3}$; therefore, the increase in an apparent density at the amount of $20 \mathrm{wt} . \%$ of PWS is $~ 78 \%$ for 10-RPG composites, $\sim 15 \%$ for 15-RPG composites and $\sim 21 \%$ for $20-R P G$ composites comparing to the neat polyurethane foam. A typical effect of the addition of inorganic particles to the reaction mixture is an increase in viscosity. The filler can induce a decrease in the reactivity of the components in the system, affecting the foam expansion, thus increasing the density of the cellular materials.

It is well known that the compressive strength is mainly influenced by the density of material, and Table 5 shows the numerical values of the mentioned parameter as well as tensile strength. Increasing com- pressive strength indicates greater bonding between PWS particles and polymeric matrix, thus anticipating better stress transfer from matrix to the filler. Compressive strength of PWS filled polyurethane foam composites at a maximum concentration of PWS has increased by $\sim 53 \%$ for 10 -RPG composites, by $\sim 31 \%$ for $15-$ RPG composites and by $\sim 23 \%$ compared to the neat polyurethane foam. The increase tendency of compressive strength reduces with the increase of RPG from $10 \mathrm{pbw}$ to $20 \mathrm{pbw}$, and this could be attributed to the fact that RPG makes resultant foams more friable, thus reducing the interfacial adhesion between PWS particles and polymer. This can be observed as well from the results of tensile strength. 10 pbw of propylene glycol in polyol mixture does not affect the tensile strength of resultant composites; therefore, the increase of tensile strength values may be seen at PWS amount varying from $5 \mathrm{wt} . \%$ to $15 \mathrm{wt} . \%$. The improved mechanical performance may be attributed to the efficient homogeneity of thermoplastic polymer matrix, reinforcing effect and sufficient dispersion of particles as well as matrix which inhibited the agglomeration and allowed uniform distribution of stress (Nandi et al. 2013) due to modification of PWS particles with $1 \%$ of coupling agent, however, 20 wt.\% of PWS reduced the mentioned parameter due to increased viscosity of the mixture and enlarged capability of PWS particles to agglomerate what can be seen from Figure 4 .

Table 5. Apparent density and mechanical properties of RPG extended and PWS filled polyurethane foam composites

\begin{tabular}{|c|c|c|c|}
\hline Amount of PWS, wt. \% & Apparent density, $\mathrm{kg} / \mathrm{m}^{3}$ & Compressive strength, $\mathrm{kPa}$ & Tensile strength, $\mathrm{kPa}$ \\
\hline \multicolumn{4}{|c|}{ 10-RPG } \\
\hline 0 & $37.7 \pm 5.5$ & $177.7 \pm 13.4$ & $191.2 \pm 11.5$ \\
\hline 5 & $41.7 \pm 1.2$ & $224.3 \pm 14.1$ & $245.7 \pm 8.72$ \\
\hline 10 & $44.5 \pm 6.9$ & $228.0 \pm 16.1$ & $368.3 \pm 9.23$ \\
\hline 15 & $54.2 \pm 1.5$ & $248.3 \pm 14.1$ & $375.3 \pm 10.5$ \\
\hline 20 & $67.4 \pm 3.2$ & $271.4 \pm 14.9$ & $253.8 \pm 13.4$ \\
\hline \multicolumn{4}{|c|}{ 15-RPG } \\
\hline 0 & $42.1 \pm 1.6$ & $184.7 \pm 17.7$ & $260.3 \pm 17.8$ \\
\hline 5 & $42.2 \pm 2.4$ & $215.6 \pm 9.74$ & $235.2 \pm 9.14$ \\
\hline 10 & $43.4 \pm 2.9$ & $237.3 \pm 12.2$ & $231.8 \pm 11.0$ \\
\hline 15 & $45.6 \pm 2.6$ & $241.3 \pm 7.80$ & $219.3 \pm 15.7$ \\
\hline 20 & $48.3 \pm 3.0$ & $242.5 \pm 18.3$ & $197.2 \pm 13.6$ \\
\hline \multicolumn{4}{|c|}{ 20-RPG } \\
\hline 0 & $41.3 \pm 1.1$ & $186.9 \pm 15.1$ & $295.1 \pm 8.12$ \\
\hline 5 & $42.1 \pm 1.1$ & $193.3 \pm 13.5$ & $285.3 \pm 12.9$ \\
\hline 10 & $42.9 \pm 2.1$ & $197.0 \pm 15.3$ & $253.5 \pm 12.3$ \\
\hline 15 & $44.9 \pm 1.7$ & $207.0 \pm 14.5$ & $241.0 \pm 16.7$ \\
\hline 20 & $50.0 \pm 3.5$ & $229.4 \pm 13.3$ & $236.9 \pm 15.2$ \\
\hline
\end{tabular}



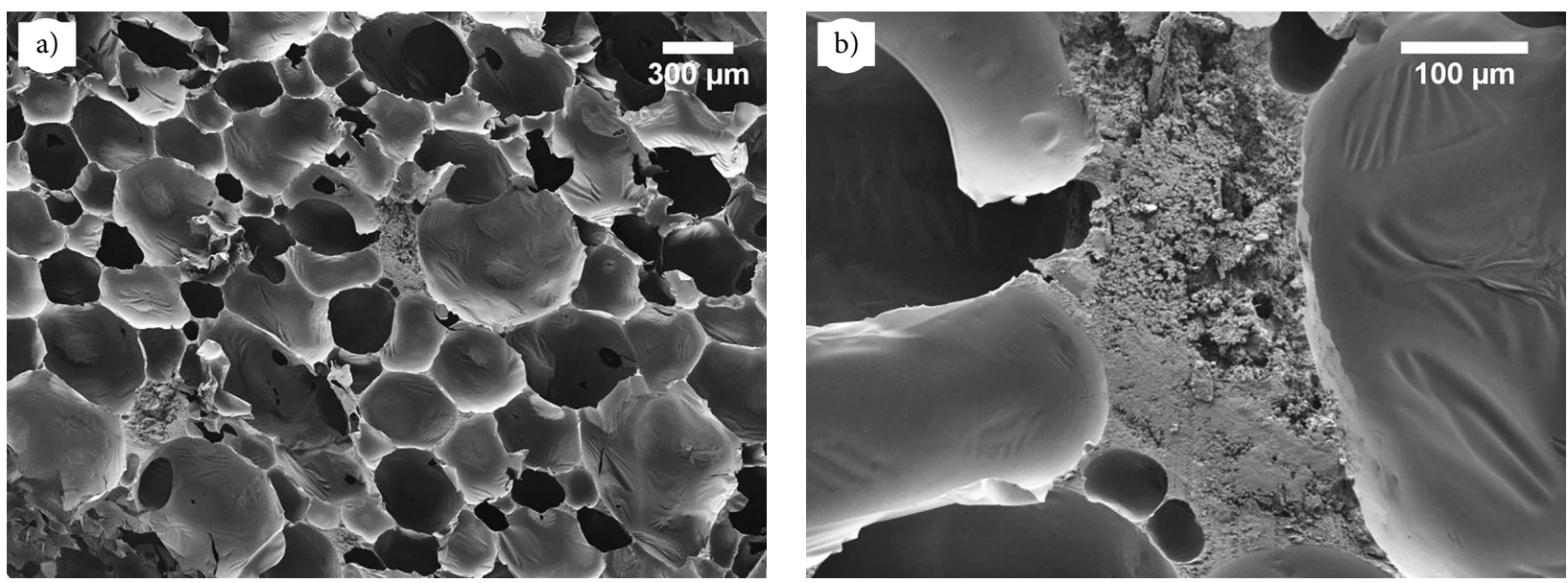

Fig. 4. Microstructure of 10 pbw of RPG extended and 20 wt.\% of PWS filled polyurethane foam composite parallel to the foaming direction: a) at $\times 35$ magnification; b) agglomerate of PWS particles at $\times 200$ magnification

Further increase in RPG from 15 pbw to 20 pbw worsens the tensile strength of PWS filled composites by $\sim 24 \%$ for 15 pbw of RPG extended composites and by $\sim 20 \%$ for 20 pbw of RPG extended composites compared to the neat polyurethane foam.

The agglomerates, as it is observed from Fig. 4a, are not distributed evenly throughout all microstructure; they are heterogeneous and have rough granulometry. The similar results have been obtained by authors (Sá e Sant'Anna et al. 2008) for composites filled with coupling agents unmodified particles.

There is only few information on such properties as dimensional stability of polyurethane foams or their composites. In order to assure the reliability of such properties for polyurethane foams from polyols obtained using natural oils, scientist use higher functionality having petroleum polyols (Kurańska et al. 2016), however, it is now of great importance to increase the bio-based matter in polymer systems. The modification of polyurethane foams with RPG with the varying amounts from $10 \mathrm{pbw}$ to $20 \mathrm{pbw}$ is basically conducted in order to reduce the excessive shrinkage of the filled polyurethane foam composites. Figure 5 presents the results of the shrinkage after 1 day after production and dimensional stability at higher temperature and humidity conditions.

It is clear that the increase in RPG reduces the shrinkage and expansion of the obtained composites. As it is seen from Figure 5a, the expansion in length and width directions after dimensional stability at higher temperature and humidity conditions test may be observed for foams with 10 pbw of RPG compared to 15 pbw and 20 pbw of RPG extended foam com- posites. Basically, the difference between the levels of expansion may be explained by the higher content of closed cells (Table 6).

The strictest requirements of product standard EN 13165:2012+A2:2016 indicate dimensional changes of $1 \%$ for length and width as well as $4 \%$ for thickness. Taking into consideration the standard deviation and the two-tailed prediction of the results, the requirements are fulfilled by composites extended with 20 pbw of RPG. Furthermore, polyurethane foam composites extended with $10 \mathrm{pbw}$ and more gives products without shrinkage, and it is controlled by urethane hard segments content which increases with the increase in the amount of RPG. The above results also indicate that the addition of low molecular weight RPG into higher molecular weight having rapeseed polyol allow obtaining foams with more stable structure at higher temperature and humidity conditions.

\section{Conclusions}

Regarding the dimensional stability, primary shrinkage after 1 day after production and density, the most suitable amount of water is $3 \mathrm{pbw}$. This is the marginal value of the amount of water when the maximum change does not exceed the limits, respectively $\leq 5 \%$ in the directions of length and width as well as $\leq 10 \%$ in the direction of thickness according to the requirements of EN 13165 for factory made rigid polyurethane foams, and density $\left(48.5 \mathrm{~kg} / \mathrm{m}^{3}\right)$ is proper to use such foams for thermal insulating purposes in building envelopes. Such amount of water has been used for the production of RPG extended and PWS particles filled polyurethane foam composites. The obtained results have 
a)

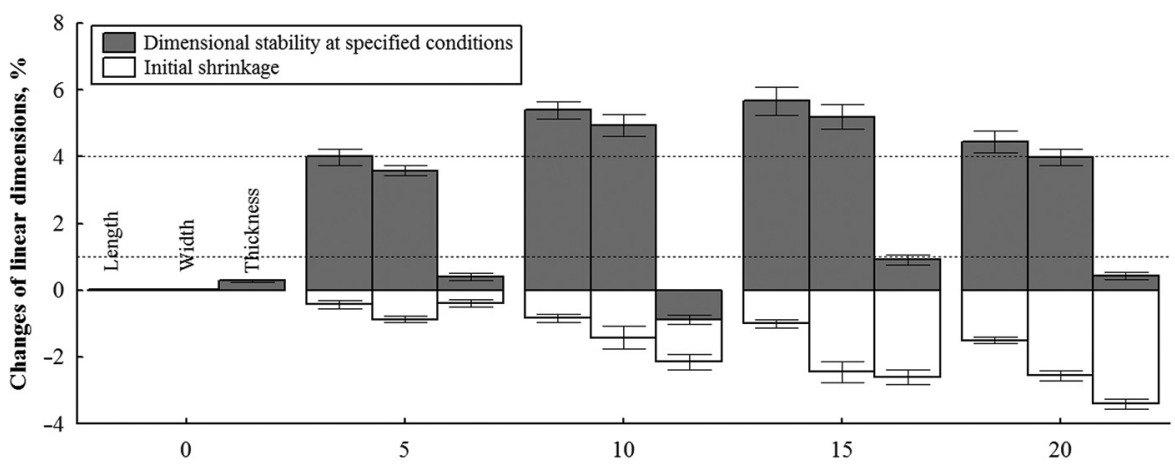

b)

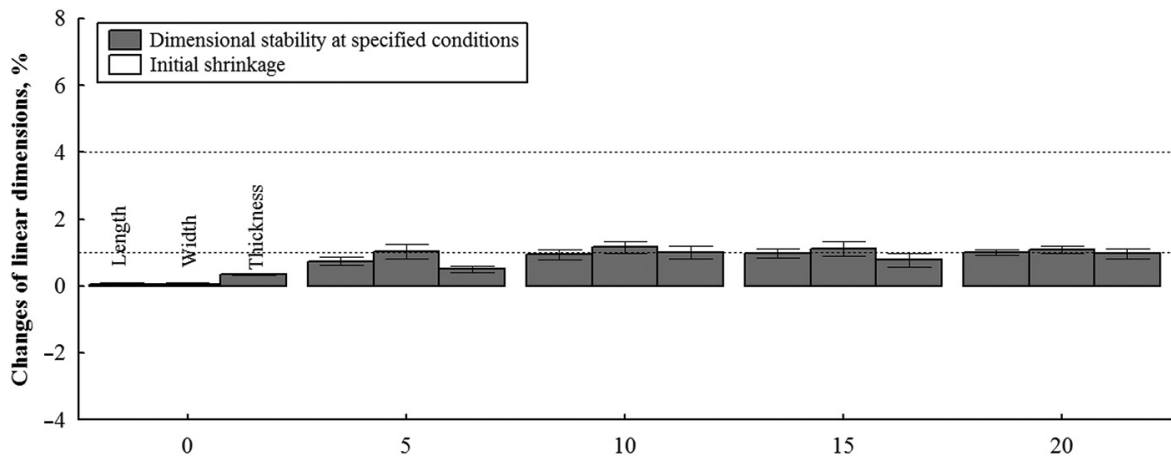

c)

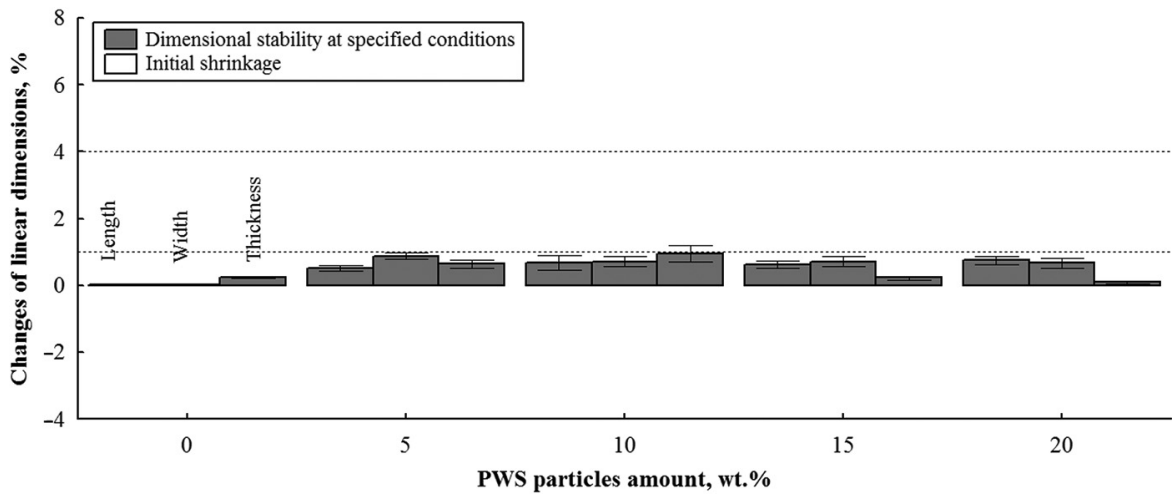

Fig. 5. Shrinkage and dimensional stability of PWS filled polyurethane foam composites modified with a) $10 \mathrm{pbw}$; b) $15 \mathrm{pbw}$ and c) 20 pbw of RPG. (-----) - minimum allowable changes in dimensions in the directions of length, width and thickness according to EN 13165:2012+A2:2016

Table 6. Closed cell content of RPG extended and PWS filled polyurethane foam composites

\begin{tabular}{|c|c|c|c|c|c|c|}
\hline \multirow{2}{*}{ Parameter } & \multirow{2}{*}{$\begin{array}{l}\text { Amount of } \\
\text { RPG, pbw }\end{array}$} & \multicolumn{5}{|c|}{ Amount of PWS, wt.\% } \\
\hline & & 0 & 5 & 10 & 15 & 20 \\
\hline \multirow{3}{*}{$\begin{array}{l}\text { Closed cell } \\
\text { content, vol. \% }\end{array}$} & 10 & $64.4 \pm 4.7$ & $79.1 \pm 3.6$ & $80.9 \pm 1.2$ & $84.3 \pm 2.2$ & $92.3 \pm 4.8$ \\
\hline & 15 & $31.3 \pm 2.4$ & $770 \pm 4.2$ & $78.9 \pm 3.7$ & $80.4 \pm 2.4$ & $82.6 \pm 4.0$ \\
\hline & 20 & $18.5 \pm 2.4$ & $77.2 \pm 2.8$ & $78.5 \pm 2.3$ & $79.1 \pm 4.2$ & $80.5 \pm 3.8$ \\
\hline
\end{tabular}

shown that 20 pbw of RPG allow obtaining composites with the sufficient dimensional stability and no shrinkage. The addition of titanate coupling agent modified PWS particles from $5 \mathrm{wt} . \%$ to $20 \mathrm{wt} . \%$, increases the compressive strength of the final composites from $\sim 26 \%$ to $\sim 53 \%$, from $\sim 17 \%$ to $\sim 31 \%$ and from $\sim 3 \%$ to $\sim 23 \%$ for, respectively, $10 \mathrm{pbw}, 15 \mathrm{pbw}$ and $20 \mathrm{pbw}$ RPG extended foam composites. It is shown that PWS amount of up to $20 \mathrm{wt} . \%$ as well as $15 \mathrm{pbw}$ and $20 \mathrm{pbw}$ of RPG can be used in order to obtain dimensionally stable water blown thermal insulation for building envelopes in the form of slab stocks. 


\section{Disclosure statement}

Authors declare that they do not have any competing financial, professional, or personal interests from other parties.

\section{References}

Agarry, S. E.; Latinwo, G. K.; Afolabi, T. J.; Kareem, S. A. 2015. Model predictive performance of filled flexible polyurethane foam, American Journal of Polymer Science 5(1): 1-9. http://dx.doi.org/10.5923/j.ajps.20150501.01

Alagi, P.; Choi, Y. J.; Hong, S. C. 2016. Preparation of vegetable oil-based polyols with controlled hydroxyl functionalities for thermoplastic polyurethane, European Polymer Journal 78: 46-60. https://doi.org/10.1016/j.eurpolymj.2016.03.003

Alam, M.; Akram, D.; Sharmin, E.; Zafar, F.; Ahmad, S. 2014. Vegetable oil based eco-friendly coating materials: a review article, Arabian Journal of Chemistry 7: 469-479. https://doi.org/10.1016/j.arabjc.2013.12.023

ASTM D7487:2016. Standard practise for polyurethane raw materials: polyurethane foam cup test. ASTM 2016. 5 p.

Belgacem, M. N.; Gandini, A. 2008. Monomers, polymers and composites from renewable resources. Amsterdam: Elsevier. $560 \mathrm{p}$.

David, J.; Vojtová, L.; Bednařík, K.; Kučerík, J.; Vávrová, M.; Jančař, J. 2009. Development of novel environmental friendly polyurethane foams, Environmental Chemistry Letters 8(4): 381-385. https://doi.org/10.1007/s10311-009-0236-8

Directive 2008/98/EC. Directive on Waste 2008/98/EC [online], [cited 10 October 2016]. 28 p. Available from Internet: http://eur-lex.europa.eu/legal-content/EN/ $\mathrm{TXT} /$ ?uri $=$ celex\%3A32008L0098

EN 13165:2012+A2:2016. Thermal insulation products for buildings - Factory made rigid polyurethane foam (PU) products Specification. LSD, 2016. $54 \mathrm{p}$.

EN 12085:2013. Thermal insulating products for building applications - Determination of linear dimensions of test specimens. LSD, 2013. 9 p.

EN 1602:2013. Thermal insulating products for building applications - Determination of the apparent density. LSD, 2013. 8 p.

EN 1604:2013. Thermal insulating products for building applications - Determination of dimensional stability under specified temperature and humidity conditions. LSD, 2013. $10 \mathrm{p}$.

EN 1607:2013. Thermal insulating products for building applications - Determination of tensile strength perpendicular to faces. LSD, 2013. $10 \mathrm{p}$.

EN 826:2013. Thermal insulating products for building applications - Determination of compression behaviour. LSD, 2013.13 p.

EN ISO 4590:2016. Rigid cellular plastics - Determination of the volume percentage of open cells and closed cells. LSD, 2016.24 p.

European Commission. 2013. Best available techniques (BAT): reference document for the production of pulp, paper and board [online]. Institute for prospective technological studies. 20 p. [cited 10 October 2016]. Available from Internet: http://eippcb.jrc.ec.europa.eu/reference/

Frías, M.; Rodríguez, O.; Sánchez de Rojas, M. I. 2015. Paper sludge, an environmentally sound alternative source of MK- based cementitious materials. A review, Construction and Building Materials 74: 37-48.

https://doi.org/10.1016/j.conbuildmat.2014.10.007

Gluth, G. J. G.; Lehmann, C.; Rübner, K.; Kühne, H. C. 2014. Reaction products and strength development of wastepaper sludge ash and the influence of alkalis, Cement and Concrete Composites 45: 82-88.

https://doi.org/10.1016/j.cemconcomp.2013.09.00

Gu, R.; Sain, M. M. 2013. Effects of wood fiber and microclay on the performance of soy based polyurethane foams, Journal of Polymers and the Environment 21(1): 30-38. https://doi.org/10.1007/s10924-012-0538-y

Hatakeyama, H.; Marusawa, T.; Hatakeyama, T. 2011. Soft-type polyurethane foams derived from molasses, Journal of Materials Science 46(23): 7475-7481.

https://doi.org/10.1007/s10853-011-5717-z

Kairytė, A.; Kirpluks, M.; Ivdre, A.; Cabulis, U.; Vejjelis, S.; Balčiūnas, G. 2016. Paper waste sludge enhanced eco-efficient polyurethane foam composites: physical-mechanical properties and microstructure, Polymer Composites, 1-9. https://doi.org/10.1002/pc.24138

Kurańska, M.; Cabulis, U.; Auguścik, M.; Prociak, A.; Ryszkowska, J.; Kirpluks, M. 2016. Bio-based polyurethane-polyisocianurate composites with an intumescent flame retardant, Polymer Degradation and Stability 127: 11-19. https://doi.org/10.1016/j.polymdegradstab.2016.02.005

Kurańska, M.; Prociak, A.; Kirpluks, M.; Cabulis, U. 2015. Polyurethane-polyisocianurate foams modified with hydroxyl derivatives of rapeseed oil, Industrial Crops and Products 74: 849-857. https://doi.org/10.1016/j.indcrop.2015.06.006

Miao, S.; Wang, P.; Su, Z.; Zhang, S. 2014. Vegetable-oil-based polymers as future polymeric biomaterials, Acta Biomaterialia 10: $1692-1704$.

https://doi.org/10.1016/j.actbio.2013.08.040

Nandi, A.; Kale, A.; Raghu, N.; Aggarwal, P. K.; Chauhan, S. S. 2013. Effect of concentration of coupling agent on mechanical properties of coir-polypropylene composite, Journal of the Indian Academy of Wood Science 10(1): 62-67. https://doi.org/10.1007/s13196-013-0094-7

Pawar, M. S.; Kadam, A. S.; Singh, P. C.; Kusumkar, V. V.; Yemul, O. S. 2016. Rigid polyurethane foams from cottonseed oil using bio-based chain extenders: a renewable approach, Iranian Polymer Journal 25: 59-68. https://doi.org/10.1007/s13726-015-0401-9

Pawlik, K.; Prociak, A. 2011. Influence of palm oil-based polyol on the properties of flexible polyurethane foams, Journal of Polymers and the Environment 20(2):438-445. https://doi.org/10.1007/s10924-011-0393-2

Pillai, P. K. S.; Li, S.; Bouzidi, L.; Narine, S. S. 2016. Metathesized palm oil: fractionation strategies for improving functional properties of lipid-based polyols and derived polyurethane foams, Industrial Crops and Products 84: 273-283. https://doi.org/10.1016/j.indcrop.2016.02.021

Sá e Sant'Anna, S.; Arlindo de Souza, D.; Marques de Araujo, D.; Carvalho, C. F.; Yoshida, M. I. 2008. Physico-chemical analysis of flexible polyurethane foams containing commercial calcium cabonate, Materials Research 11(4): 433-438. https://doi.org/10.1590/S1516-14392008000400009 
Thirumal, M.; Khastgir, D.; Singha, N. K.; Manjunath, B. S.; Naik, Y. P. 2008. Effect of foam density on the properties of water blown rigid polyurethane foam, Journal of Applied Polymer Science 108: 1810-1817. https://doi.org/10.1002/app.27712

Usman, M. A.; Adeosun, S. O.; Osifeso, G. O. 2012. Optimum calcium carbonate filler concentration for flexible polyurethane foam composite, Journal of Minerals and Materials Characterization and Engineering 11(3): 311-320. https://doi.org/10.4236/jmmce.2012.113023

Wik, V. M.; Aranguren, M. I.; Mosiewicki, M. A. 2011. Castor oil-based polyurethanes containing cellulose nanocrystals, Polymer Engineering and Science 51(7): 1389-1396. https://doi.org/10.1002/pen.21939
Xiaobin, L.; Hongbin, C.; Zhang, Y. 2008. Properties of water blown rigid polyurethane foams with different functionality, Journal of Wuhan University of Technology 23(1): 125-129. https://doi.org/10.1007/s11595-006-1125-7

Zule, J.; Černec, F.; Likon, M. 2007. Chemical properties and biodegrability of waste paper mill sludges to be used for landfill covering, Waste Management and Research 25(6): 538-546. https://doi.org/10.1177/0734242X07079188

Agnè KAIRYTE் is a PhD student in Materials Engineering (08T) of Vilnius Gediminas Technical University, Scientific Institute of Thermal Insulation, Laboratory of Thermal Insulating Materials. Research interests are development and research of bio- and petroleum based polymeric materials and their composites.

Aiga IVDRE is a scientific assistant at Latvian State Institute of Wood Chemistry, Polymer Laboratory, and PhD student at Riga Technical University. Her research interests are development and research of rigid polyurethane foams from renewable materials and chemically recycled PET.

Saulius VAITKUS is a senior scientist at Vilnius Gediminas Technical University, Scientific Institute of Thermal Insulation, Laboratory of Thermal Insulating Materials. Research interests: investigations of physical-mechanical and thermal-technical characteristics of thermal insulating materials and products; development and research of thermal insulation from local renewable resources, natural fibres. 